treatment. Corticosteroids have been used increasingly since 1952 , and in Great Britain the use of pressurized aerosols containing sympathomimetics has increased rapidly since 1960.

ADDENDUM.-Since this paper was submitted figures for 1966 in New Zealand supplied by the Public Health Statistician for New Zealand have been made available to us oy Dr. Gandevia. These reveal an apparent increase in deaths attributed to asthma for the age group 9-54 years. Agespecific death rates are not yet available, but Dr. Gandevia suggests that an upward trend in mortality may now be occurring (Gandevia, personal communication).

We are grateful to the Registrar General of England and Wales for supplying many of the data, and for supplying them with minimal delay. We are grateful also to the Ministry of Health for information about the sale of aerosol bronchodilators; and to Miss A. M. Hetzel, Chief of the Statistical Resources Section of the Division of Vital Statistics, U.S. Public Health Service, Dr. B. Gandevia, Associate Professor in Thoracic Medicine, the Prince Henry Hospital, Little Bay, New South Wales, Professor S. Koller, Professor of Medical Statistics, University of Mainz, and Dr. D. L. Crombie,
Director of the Records and Statistics Unit of the Royal College of General Practitioners, for information about the mortality from asthma in the United States, Australia, and the German Federal Republic, and for morbidity data in Britain.

Dr. F. E. Speizer was supported by the National Center for Air Pollution, Bureau of Disease Prevention and Environmental Control, U.S. Public Health Service.

\section{REFERENCES}

Detty, T. L. (1966). Management of Chronic Obstructive Lung Diseases, Public Health Service Publication, No. 1457, Washington.

Ford, R. M. (1966). Med. f. Aust., 2, 196

Fry, J. (1962). Morbidity Statistics from General Practice, Vol. 3, pp. 15-33. H.M.S.O., London.

Gandevia, B. (1967). Brit. med. F., 2, 441.

Greenberg, M. J., and Pines, A. (1967). Ibid., 1, 563.

Kessler, A., and Geller-Bernstein, C (1966).' F. Amer. med. Ass., 196, 458.

Ministry of Technology (1967). The Investigation of Atmospheric Pollution 1958-1966: 32nd Report. H.M.S.O., London.

Richards, W., and Patrick, J. R. (1965). Amer. F. Dis. Child., 110, 4.

Smith, J. M.' (1966). Lancet, i, 1042.

Smith, J. M. (1966), Lancet, 1, 1042. Ame R. O., and Dickerson, R. C. (1965). 'Arch. environm. Hith, 10, 148. World Health Organization (1966). Epidem. vital Statist. Rep., 19, 525.

\title{
Investigation into Use of Drugs Preceding Death from Asthma
}

\author{
F. E. SPEIZER,* M.D. ; R. DOLL, $†$ M.D., F.R.C.P., F.R.S. ; P. HEAF, $\ddagger$ M.D., F.R.C.P. ; L. B. STRANG, $§$ M.D., F.R.C.P.
}

Brit. med.F., 1968, 1, 339-343

The annual number of deaths attributed to asthma has increased progressively in England and Wales since 1960. The increase has been substantial at all ages, but has been most pronounced in adolescence and young adult life. Between 1959 and 1966 the death rate increased three times at ages 5 to 34 years and nearly eight times at ages 10 to 14 years. Possible reasons for this change have been examined previously, when it was consluded that the increase was real and likely to be due, in large part, to changes in treatment leading to an increased case fatality (Speizer, Doll and Heaf, 1968). We have therefore sought information about the mode of death and the method of treatment used during and preceding the terminal illness in a consecutive series of deaths attributed to asthma in young persons.

\section{Data}

Copies of death certificates were provided by the Registrar General for all deaths in persons aged 5 to 34 years which were registered in England and Wales in the period 1 October 1966 to 31 March 1967, and in which asthma was described as the underlying cause. On receipt of the certificates, which was usually within two months of the date of death, we sought from the local executive councils, the coroners who had signed the vertificates, or the hospitals where the deaths were recorded, the names of the general practitioners on whose lists the patients were registered. A standard questionary was then mailed to the general practitioner inquiring about the therapy the patient had received during and before the terminal illness, and whether death had been anticipated. When death was recorded at

- U.S. Public Health Service Fellow, Medical Research Council's Statistical Research Unit.

† Director, Medical Research Council's Statistical Research Unit.

\& Chest Physician, University College Hospital, London W.C.1.

S Professor of Paediatrics, University College Hospital Medical School, London W.C.1.

Requests for reprints should be addressed to Dr. R. Doll, University College Hospital Medical School, 115 Gower Street, London W.C.1. hospital a similar questionary was also mailed to the hospital physician. At the time the inquiry was begun interest centred on the possible effect of corticosteroids and no direct questions were included about the use of pressurized aerosols. When death had been certified by a coroner, or the death certificate indicated that a post-mortem examination had been carried out, inquiries were also made about the necropsy findings.

The number of death certificates received and the number of questionaries returned are shown in Table I. In four instances no inquiries could be made as the name of the relevant general practitioner could not be ascertained. Two physicians did not respond to multiple inquiries, and one knew nothing about the patient, who had only just been entered on his list, and returned a blank questionary. In all, therefore, we obtained information relating to $96 \%$ of the deaths (177 out of 184). The forms were, in general, completed fully and carefully and many practitioners provided a great amount of detailed information. All the information requested was not, however, always available and some data refer to slightly smaller total numbers.

Fifty-two deaths were recorded in hospital and letters were sent to 52 hospital consultants. All replied. Few could provide any information beyond that associated with the management of the terminal episode, and six of the question-

\begin{tabular}{|c|c|c|c|c|c|}
\hline \multirow{3}{*}{$\begin{array}{l}\text { Death } \\
\text { Certified by }\end{array}$} & \multirow{3}{*}{$\begin{array}{l}\text { No. of } \\
\text { Deaths }\end{array}$} & \multicolumn{4}{|c|}{ Questionaries to: } \\
\hline & & \multicolumn{2}{|c|}{ General Practitioner } & \multicolumn{2}{|c|}{ Hospital Consultant } \\
\hline & & No. & $\begin{array}{l}\text { No. } \\
\text { Returned }\end{array}$ & $\begin{array}{l}\text { No. } \\
\text { Sent }\end{array}$ & $\begin{array}{c}\text { No. } \\
\text { Returned }\end{array}$ \\
\hline $\begin{array}{l}\text { General practitioner } \\
\text { Coroner } \ldots \\
\text { Hospital consultant }\end{array}$ & $\begin{array}{r}44 \\
109 \\
31\end{array}$ & $\begin{array}{r}43 \\
106 \\
31\end{array}$ & $\begin{array}{r}43 \\
104 \\
31\end{array}$ & $\overline{21}$ & $\overline{21}$ \\
\hline All sources & 184 & $180^{*}$ & $178 t$ & 52 & $52 \ddagger$ \\
\hline
\end{tabular}


aries were returned blank. For most analyses we have therefore used the data provided by the general practitioners and have used the hospital data only for the analysis of necropsy findings and occasionally to amplify the practitioners' replies.

Information about the post-mortem findings was obtained for 100 of the 109 deaths certified by coroners and for 13 of the 15 other deaths which were known to have been followed by post-mortem examination. Necropsy data are therefore available for $61 \%$ of all deaths and for $91 \%$ of deaths in which a post-mortem examination is known to have been made.

\section{Results}

\section{Clinical Characteristics}

The sex and age distribution of the patients at death is shown in Table II. The total numbers of males and females were approximately equal (89 and 95 respectively). As in other data, however, there was a male excess under 20 years of age and a female excess above 25 years.

TABLE II.-Number of Deaths by Sex and Age (Number for Which Completed Questionaries Were Received Shown in Parentheses)

\begin{tabular}{c|c|c|c}
\hline $\begin{array}{c}\text { Age of } \\
\text { Subject } \\
\text { (in Years) }\end{array}$ & \multicolumn{2}{|c|}{ No. of Deaths in: } & Total Deaths \\
\hline $5-9$ & Males & Females & \\
$10-14$ & 6 & 1 & $7(7)$ \\
$15-19$ & 12 & 12 & $24(24)$ \\
$20-24$ & 16 & 15 & $31(31)$ \\
$25-29$ & 16 & 25 & $33(31)$ \\
$30-34$ & 19 & 25 & $45(42)$ \\
\hline Ages 5-34 & 89 & 95 & $184(177)^{*}$ \\
\hline
\end{tabular}

In three cases the cause of death was attributed to asthma after a coroner's post-mortem examination, but the diagnosis was disputed by the practitioner who had been looking after the patient. Brief details are as follows:

Case 1.-Man aged 24, under practitioner's care for six years without ever having attended for asthma or any other illness. No drugs prescribed. Doctor sent for because patient had "fainted"; found dead on arrival. According to wife's statement he had never had any illness previously; he suddenly complained of pain in his chest, went to sit down, and was found dead in a chair 20 minutes later. Diagnosis: coronary thrombosis. Post-mortem report: Patches of atheroma in anterior descending branch of left coronary artery, but no evidence of occlusion. Both lungs congested and moderately voluminous; small bronchi contained thick mucus. Cause of death: status asthmaticus.

Case 2.-Woman aged 29, under practitioner's care for four years. Lifelong history of bronchitis and bronchiectasis not specifically asthmatic; had been in hospital for bronchiectasis. No A.C.T.H., corticosteroids, or bronchodilators given ; treated with expectorants, antibiotics, and diuretics. Terminal episode lasted half an hour. Diagnosis : right heart failure due to long-standing bronchiectasis. Post-mortem report: Fingers clubbed. Pericardiac sac contains a slight excess of fluid; the heart ( $320 \mathrm{~g}$.) flabby and pinkish brown; both ventricles dilated, and right shows marked hypertrophy, being almost as thick as the left. Left pleural sac contains 2 oz. $(57 \mathrm{ml}$.) of clear effusion and the right is largely obliterated by old adhesions. The distended lungs show generalized emphysema and are generally dry ; moderate bronchiectasis in right middle and lower lobes and a general purulent bronchitis. Cause of death: cardiac failure as a consequence of bronchial asthma and bronchiectasis.

Case 3.-Woman aged 29, under practitioner's care for one year. The doctor had treated her for "mental illness" but was " not aware that she had asthma"; the only drug he had prescribed was chloral hydrate. Post-mortem report: The lungs were moderately distended with air. Bronchi congested and contained plugs of thick tenacious mucus. Gastric mucosa intensely congested. All other organs completely normal. Histological examination of lungs showed the appearance of bronchial asthma. Cause of death: status asthmaticus.
These cases have been excluded from subsequent analyses except for the analysis of the necropsy data.

Most of the remaining deaths appear to have occurred in persons with mild to moderate asthma since childhood, rather than in severe respiratory cripples. The mean duration of asthma in 159 patients for whom it was estimated was 13.1 years and the median age of onset was 7.0 years. Only five persons, all of whom died when over 15 years of age, had had asthma for less than one year. The asthma had at some time been severe enough for $81 \%$ of the patients to have been referred to a chest physician (136 out of 168), but only $59 \%$ had ever been admitted to hospital ( 95 out of 161).

The characteristics of the terminal illness are shown in Table III. Death was sudden and unexpected in $80 \%$ of cases $(137$ out of 171), and $39 \%$ of the practitioners had regarded the terminal illness as "not severe" (67 out of 171). In 133 cases the practitioners were reasonably confident that they could estimate the duration of the terminal episode. In over a quarter of these (37 out of 133) the patients died in less than one hour and only $39(29 \%)$ survived 24 hours or more. That death was commonly sudden and unexpected is confirmed by the fact that $59 \%$ of the deaths (109 out of 184) were certified by coroners.

TABLE III.-Characteristics of the Terminal Episode (All Patients with

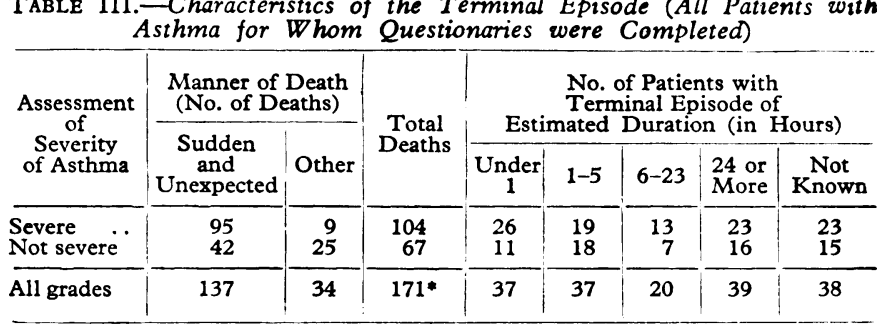

* Severity of asthma and suddenness of death not stated for three patients.

As previously noticed, there were 31 cases in which patients had been certified by the hospital staff as dying of asthma. An additional 21 patients whose death was reported by hospitals were certified by coroners. The hospital consultant was not able to supply any information on six of these patients. Of the remaining 46 patients 10 arrived at hospital dead, and an additional four died within one hour. Twenty-two patients survived for 24 hours or more, and even among these death occurred suddenly and unexpectedly in $15(68 \%)$.

\section{Necropsy Findings}

The classical gross pathological finding in asthma of voluminous overdistended lungs which do not collapse when removed from the chest cavity was described in 110 out of 113 post-mortem reports $(97 \%) .^{1}$ In all but seven of these the second most important classical finding - thick tenacious mucus plugging of the smaller bronchi-was also present. Additional evidence of emphysema was described in 27 cases. Few of the protocols contained information about microscopical examination; those that did described an abundance of eosinophils in the mucoid material. The three cases not typical of asthma showed, respectively, completely normal lungs, bilateral collapse with unilateral tension pneumothorax, and advanced bronchitis.

Pulmonary findings additional to those of asthma occurred infrequently. Five cases were reported with inhalation of vomitus, four with pulmonary oedema, three with purulent pneumonia, two with bronchitis, and one each with haemorrhagic pneumonia, bronchitis and bronchiectasis, and bilateral apical pulmonary tuberculosis. The only other findings of major importance were two cases with, respectively, myocardial infarction and pericardial effusion.

${ }^{1}$ Including Cases 1, 2, and 3 described previously. 
We attempted to compare the presence or absence of right ventricular dilatation and hypertrophy with the clinical grading of severity of the asthma. The comparison could be made in only 103 of the 113 cases. $^{2}$ In $47 \%$ of these one or other condition was described. Hypertrophy was present in 7 of the 44 not-severe asthmatics $(16 \%)$ and in 15 of the 59 severe asthmatics $(25 \%)$. Dilatation was present in 4 of the 18 patients who did not die suddenly and unexpectedly (22\%), and in 30 out of 85 of those who did (35\%). Neither of these differences is statistically significant ( $P$ in each case is approximately 0.3 ), but the trends are in the expected directions.

In 58 of the post-mortem reports a comment was made about the endocrine system, or specifically about the adrenal glands. Marked atrophy of the adrenals was noted in six cases in all of which the subject had been taking corticosteroids-for three and a half days in one instance, less than six months in another, and over two years in four.

\section{Use of Corticosteroids ${ }^{3}$}

Initially we had supposed that any patient with asthma severe enough to cause death was likely to have received corticosteroids. In fact, a substantial number of patients had not been regarded as suffering from severe asthma and more than a quarter ( 50 out of 173 ) were never given any corticosteroids at all. Thirty-one patients had received corticosteroids, but the treatment had been stopped for between a few days (three patients) and over one year (eight patients), and no corticosteroids were given in the terminal episode. In these cases the failure to give further corticosteroids can usually be attributed to the brevity of the terminal episode-21 of the 23 patients for whom its duration could be estimated (91\%) dying in less than three hours. The remaining 92 patients were either receiving corticosteroids at the time their terminal episode began or were given them as emergency treatment. Details of the schedules used are summarized in Table IV. A

TABLE IV.-Use of Corticosteroids Before and During Terminal Episode (All Patients with Asthma for Whom Questionaries were Completed)

\begin{tabular}{|c|c|c|c|c|c|}
\hline \multirow{3}{*}{$\begin{array}{l}\text { Treatment in } \\
\text { Terminal Episode }\end{array}$} & \multicolumn{4}{|c|}{$\begin{array}{l}\text { No. of Patients Treated Before the } \\
\text { Terminal Bpisode }\end{array}$} & \multirow{3}{*}{$\begin{array}{c}\text { Total } \\
\text { Patients }\end{array}$} \\
\hline & \multirow[b]{2}{*}{$\begin{array}{l}\text { Without } \\
\text { Cortico- } \\
\text { steroids }\end{array}$} & \multicolumn{3}{|c|}{ With Corticosteroids } & \\
\hline & & $\begin{array}{l}\text { Within } \\
2 \\
\text { Weeks* }\end{array}$ & $\begin{array}{c}2-52 \\
\text { Weeks } \\
\text { Previously }\end{array}$ & $\begin{array}{l}\text { More than } \\
1 \text { Year } \\
\text { Previously }\end{array}$ & \\
\hline \multirow{7}{*}{$\begin{array}{c}\text { No corticosteroids . } \\
\text { Corticosteroids given: } \\
\text { Single injection . . } \\
\text { High dose before } \\
\text { death: } \\
\text { (a) Steady level } \\
\text { (b) Moderate or } \\
\text { low dose } \\
\text { increased } \\
\text { Moderate or low } \\
\text { dose unaltered .. } \\
\text { Dose decreased . } \\
\text { before death: } \\
\text { (a) High at first } \\
\text { (b) Moderate or } \\
\text { low at first } \\
\text { Regimen not known } \\
\text { All treatments .. }\end{array}$} & 50 & 3 & 20 & 8 & 81 \\
\hline & 3 & 4 & 2 & 0 & 9 \\
\hline & 3 & 2 & 3 & 2 & 10 \\
\hline & 0 & 7 & 6 & 0 & 13 \\
\hline & 0 & 31 & 8 & 1 & 40 \\
\hline & 0 & 5 & 0 & 0 & \\
\hline & $\begin{array}{r}1 \\
2 \\
59\end{array}$ & $\begin{array}{r}4 \\
3 \\
59\end{array}$ & $\begin{array}{r}1 \\
2 \\
42\end{array}$ & $\begin{array}{r}1 \\
1 \\
13\end{array}$ & $\begin{array}{c}7 \\
8 \\
173 \ddagger\end{array}$ \\
\hline
\end{tabular}

* Mostly on corticosteroids regularly at the start of the terminal episode.

‡ History of corticosteroids use not stated for one patient.

quarter of the patients (23) received high doses of corticosteroids immediately before death, but in the majority the dose was maintained at a moderate or low level (40 patients) or was tapered (12 patients). It may be, therefore, that many patients were given insufficient steroids to overcome adrenal suppression as a result of previous steroid therapy or the stress of the disease. It must be remembered, however, that death often

'The additional 10 cases were three for which the severity was unknown, four for which no questionary was completed, and three which were regarded by the general practitioners as not asthmatic.

- Six patients had been given A.C.T.H. For the purpose of the present analysis these have been included with those given corticosteroids. occurred suddenly and in the absence of apparent serious respiratory distress, so that there may have been no obvious indications for increasing the dose.

Examination of the data for the patients who died at ages 10 to 19 years provides no evidence that the distribution of corticosteroid usage in this group differed from that in patients at other ages. Seventeen of the 55 patients were never given corticosteroids at any period $(31 \%) ; 11$ had corticosteroids before the terminal episode but not in it $(20 \%) ; 1$ received corticosteroids only in the terminal episode; and 26 received corticosteroids both in this episode and previously (47\%). These proportions are very similar to those recorded for all patients aged 5 to 34 years in Table IV.

\section{Use of Inhaled Bronchodilators}

At the start of the inquiry we had no special concern for any particular form of therapy other than corticosteroids; doctors were therefore asked only to name other drugs that were known to have been used in the last month of the patient's life. In response to this question 130 doctors specified that inhalant preparations of bronchodilators had been so used. In the light of this evidence a further letter was sent to those doctors who had not mentioned these preparations, inquiring specifically about them, and all responded. We have, therefore, evidence that bronchodilators were being inhaled by at least $86 \%$ of the patients (150 out of 174), but we do not know how recently they had been used when the patient died. Eighteen patients had definitely not used them, and in the remaining six instances the doctors did not know for certain whether they had been used or not.

Isoprenaline was used much more commonly as an inhalant than any other sympathomimetic drug. Its use was mentioned directly or indirectly under a trade name in 108 cases $(72 \%$ of specified types). Other specified sympathomimetics used in this way were orciprenaline ( 33 cases) and adrenaline ( 9 cases). In four of the cases in which adrenaline was used the preparation was in the form of a simple spray; in all other cases the sympathomimetic was given in the form of a pressurized aerosol.

The frequency with which pressurized aerosols were used in the different clinical categories is shown in Tables V and VI. Very little difference was found between those patients who were characterized clinically as severe asthmatics and those considered clinically to be not severe-89 out of $102(87 \%)$ against 54 out of $63(86 \%)$. The difference was somewhat larger between those who died suddenly and unexpectedly (116 out of 131 , or $89 \%$ ) and those who died otherwise (27 out of 34 , or $79 \%$ ), but it was not statistically significant ( $P$ approximately 0.2 ). Pressurized aerosols had also been used by nearly all patients irrespective of the duration of the terminal episode. It may be noted that only 2 of the 37 patients who died within an hour of the start of the episode had not used these preparations, and the proportion (5\%) is less than that recorded for

Table V.-Use of Pressurized Aerosol Bronchodilators in Different Clinical Categories (All Patients with Asthma for Whom Questionaries were Completed

\begin{tabular}{|c|c|c|c|c|c|}
\hline \multirow{2}{*}{\multicolumn{2}{|c|}{ Clinical Category }} & \multicolumn{3}{|c|}{ No. of Patients } & \multirow{2}{*}{$\begin{array}{c}\text { Total } \\
\text { No. of } \\
\text { Patients }\end{array}$} \\
\hline & & $\begin{array}{c}\text { Known to } \\
\text { have Used } \\
\text { Aerosols }\end{array}$ & $\begin{array}{c}\text { Known Not } \\
\text { to have Used } \\
\text { Aerosols }\end{array}$ & $\begin{array}{c}\text { Aerosol } \\
\text { History } \\
\text { Not Known }\end{array}$ & \\
\hline $\begin{array}{l}\text { Severe asthma: } \\
\text { Death sudden } \\
\text { Death not sudden }\end{array}$ & $\because$ & $\begin{array}{r}82 \\
7\end{array}$ & $\underset{2+}{11 *}$ & $\begin{array}{l}2 \\
0\end{array}$ & $\begin{array}{r}95 \\
9\end{array}$ \\
\hline $\begin{array}{l}\text { Asthma not severe: } \\
\text { Death sudden } \\
\text { Death not sudden } \\
\text { Category not known }\end{array}$ & $\because$. & $\begin{array}{r}34 \\
20 \\
3 \\
\end{array}$ & $\begin{array}{l}4 \\
5 \\
0\end{array}$ & $\begin{array}{l}4 \\
0 \\
0\end{array}$ & $\begin{array}{r}42 \\
25 \\
3\end{array}$ \\
\hline All categories .. & .. & 146 & 22 & 6 & 174 \\
\hline
\end{tabular}

* Three on inhalant sprays. + One on inhalant spray. 
all other patients with known durations (13\%). The difference, however, is again not statistically significant and may well be attributable to chance ( $\mathrm{P}$ approximately 0.2 ).

Table VI.-Use of Pressurized Aerosol Bronchodilators by Estimated Duration of Terminal Episode (All Patients with Asthma for Whom Questionaries were Completed)

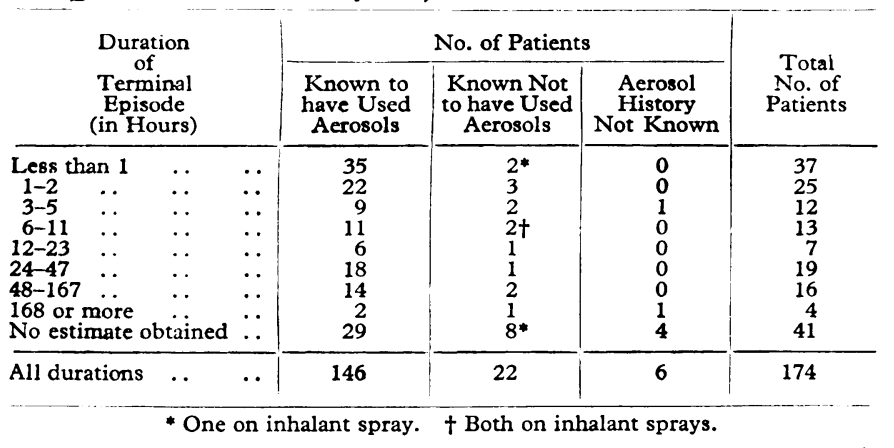

Examination of the data for the patients who died at ages 10 to 19 years provides no evidence that the distribution of usage of pressurized aerosols in this group differed from that in patients at other ages. Nine of the 55 patients had not used them in the last month of their life (16\%)-a proportion slightly greater than that shown for all patients aged 5 to 34 years in Table V $(13 \%)$.

Excessive use of pressurized aerosols was reported by 29 general practitioners without specific inquiry having been made. The reports ranged from a vague implication, such as "tended to use aerosols too frequently" or "suspicion of excess aerosol at death," to direct observations such as "died clutching aerosol" and a detailed account of the amount consumed. In extreme cases the use of as many as two canisters per day or two in two hours was reported.

\section{Other Therapy}

Almost all the patients received bronchodilators by mouth during the last month of life. Ephedrine alone was used in almost $30 \%$ of patients, and it was used by most of a further $30 \%$ who used more than one preparation at a time. These preparations usually included ephedrine alone and ephedrine in combination with theophylline and a sedative. Fifty per cent. of the patients for whom information is available were given additional bronchodilators-usually in the form of parenteral adrenaline or aminophylline-in the terminal episode.

Sedatives were used, either alone or in preparations combined with bronchodilators, in $39 \%$ of the patients ; and antibiotics had been given to $46 \%$. Neither phenothiazines, nor barbiturates, nor any other group of drugs was used by more than $15 \%$ of patients, so that it does not seem likely that any drug other than cortico eroids or bronchodilators could have been responsible for the increase in mortality.

\section{Discussion}

The results of our inquiry strongly suggest that the great majority of deaths attributed to asthma in young people are correctly ascribed. Necropsy findings were similar to those reported previously when death occurred during status asthmaticus, and there was seldom evidence of any additional pathology. Many of the patients had been regarded as only moderately affected, but the fact that two-thirds of them (114 out of 173) had received corticosteroid treatment at some time before their terminal illness indicates that as a group they were severely affected. Indeed we have to conclude that the severity of the illness was often underestimated. Deaths were frequently unexpected and occurred outside hospital, which suggests that the patients may have been living closer to the limits of their ventilatory reserve than was realized. Certainly measurements of ventilatory capacity in asthmatics often reveal more severe degrees of impairment than are suggested from the clinical signs, and some asthmatic children simply learn not to waste their breath by complaining.

The inquiry has provided information about the circumstances in which the patients died but no clear indication of the cause for the increase in the number of deaths. Adrenal suppression due to corticosteroid treatment may have contributed to the death of some patients, but $34 \%$ (59 out of 173 ) had never received corticosteroids until their terminal illness; marked adrenal atrophy was mentioned in only 6 of the 113 necropsy reports ; and there was no mention of hypotension or any other clinical feature of hypoadrenalism. The increase in mortality did not begin to appear until nearly 10 years after the introduction of corticosteroids for the treatment of asthma, and it seems unlikely that they can have been responsible for any substantial part of it.

Aerosol bronchodilators could affect the patient adversely by a number of mechanisms. Excessive amounts of a sympathomimetic, absorbed from the bronchi over a prolonged period, could cause ventricular irritability and fatal arrhythmia, or they could affect the viscosity of the bronchial mucus and lead to plugging of the bronchi. Alternatively, the inhaled bronchodilator may reduce airways obstruction without producing a corresponding improvement in arterial oxygenation (Daly and Howard, 1965 ; Field, 1967 ; Knudson and Constantine, 1967 ; Palmer and Diament, 1967). This may perhaps enable the patient to tolerate an unsatisfactory level of oxygen uptake and to come nearer to respiratory insufficiency before he, or his doctor, asks for hospital admission. The increase in the use of pressurized aerosol bronchodilators correlates closely with the increase in asthma mortality in Britain (Speizer et al., 1968), and we obtained evidence that they had been prescribed for $84 \%$ of the patients (146 out of 174). Accounts of the excess use of aerosols have been obtained in some cases, but decisive evidence to incriminate them is lacking.

\section{Summary}

Copies of death certificates were provided by the Registrar General for all deaths attributed to asthma in persons aged 5 to 34 years which were registered in England and Wales in the last quarter of 1966 and the first quarter of 1967. Information was obtained from the relevant general practitioners about 177 of the 184 subjects, and necropsy data were obtained for 113 of the 124 cases in which a post-mortem examination was known to have been made.

Ninety-eight per cent. of the subjects for whom evidence was obtained were known to have been suffering from asthma, and signs of severe asthma (overdistended lungs and small bronchi plugged with mucus) were found in $91 \%$ of necropsies $(57 \%$ of all deaths). Evidence that death might have been due to any other pathological condition was rare.

Death was sudden and unexpected in $81 \%$ of the subjects (137 out of 171), and $59 \%$ of all deaths were referred to coroners. In $39 \%$ of cases (67 out of 171 ) the practitioner had not regarded the patient as suffering from severe asthma in his terminal episode.

Corticosteroids and sympathomimetic preparations were the only drugs to have been used by a large proportion of patients. Two-thirds of the patients had received corticosteroids before the terminal episode, but detailed information about their use provided no suggestion that excess use could have been responsible for any large proportion of the deaths. Eighty-four per cent. of the patients were known to have used pressurized aerosol bronchodilators, and several instances of their use in excess were described. Routine inquiries about their use in the 
hours immediately preceding death were not made, and further evidence is required before their effect can be assessed adequately.

We are grateful to the Registrar General for providing us with copies of the death entries relating to young persons who had died of asthma, to the many doctors and coroners who replied to our questions and made their records available to us, and to Mrs. Ranjana Ash for help in coding and analysing the data.
Dr. F. E. Speizer was supported by the National Center for Air Pollution, Bureau of Disease Prevention and Environmental Control, U.S. Public Health Service.

\section{REFERENCES}

Daly, J. J., and Howard, P. (1965). Thorax, 20, 324

Field, G. B. (1967). Clin. Sci., 32, 279.

Knudson, R. J., and Constantine, H. P. (1967), F. appl. Physiol., 22, 402

Palmer, K. N. V., and Diament, M. L. (1967). Lancet, 2, 383

Speizer, F. E., Doll, R., and Heaf, P. (1968). Brit. med. F., 1, 335

\title{
Some Problems of Permanent Artificial Pacing*
}

\author{
M. S. GOTSMAN, M.D., M.R.C.P., M.R.C.P.GLASG. ; L. W. PILLER, F.S.C.T. ; W. BECK, M.MED., M.SC., M.R.C.P. \\ C. N. BARNARD, D.SC., M.D., M.MED., M.S., PH.D., F.A.C.S. \\ V. SCHRIRE, M.D., M.SC., PH.D., F.R.C.P., F.R.C.P.ED., F.A.C.C.
}

Brit. med. 9., 1968, 1, 343-346

Patients with complete heart block who have symptoms which cannot be controlled by sympathomimetic amines or vagolytic drugs are best treated by artificial pacing (Chardack, Gage, Federico, Schimert, and Greatbatch, 1964 ; Bluestone, Davies, Harris, Leatham, and Siddons, 1965 ; Gotsman, Beck, Barnard, and Schrire, 1966 ; Furman, Escher, Schwedel, and Solomon, 1966 ; Lagergren, 1967 ; Parsonnet, Zucker, Gilbert, Brief, and Alpert, 1967).

Though many different systems have been devised and used, sach method has its own particular advantages and problems. Experience with the various techniques is accumulating from many countries, but the limiting factors are battery exhaustion, failure of electronic components, fatigue of electrode wires or insulation, or biological reaction to an implanted system Sowton and Davies, 1964 ; Davies and Siddons, 1965 ; Glass, 1965).

We describe our own methods and experience to show that pacing is relatively safe and that it is possible to treat patients who live far from the major cardiac clinic or consultant medical services.

\section{Patients}

Permanent artificial pacing was undertaken in 48 patients with complete heart block. Five had intermittent complete heart block but were treated for Stokes-Adams attacks. Twelve patients were in severe heart failure, three had symptoms of severe cerebrovascular insufficiency due to a low cardiac output which was improved by an artificial increase in heart rate, and the remainder had repeated incapacitating Stokes-Adams attacks. Seven patients had a previous proved myocardial infarction (Gotsman, Beck, Piller, and Schrire, 1967 ; Davies, Redwood, and Harris, 1967), one had toxoplasmosis, another had complete heart block before repair of an endocardial cushion defect, while in the remainder an obvious cause could not be found. They were older subjects, and we presume that the block was due to fibrosis of the cardiac skeleton (Lenègre and Moreau, 1963 ; Lev, 1964). Nearly all the patients were given an initial trial of medical treatment with atropine, ephedrine, and long-acting isoprenaline. Pacemaking was not used in 20 other patients with complete heart block who were free of symptoms or had symptoms which could be controlled by drug therapy.

- From the Cardiac Clinic, Departments of Medicine and Surgery, Groote Schuur Hospital, and the Cardiovascular Pulmonary Research Group, University of Cape Town. Supported in the Department of Medicine by the Council for Scientific and Industrial Research.

\section{Techniques}

Ninety-one units were implanted in 48 patients in the three and a half years from July 1964 to November 1967. We elected to use a totally implanted system, as patients preferred not to have exteriorized wires and external generators. Six different systems were used; with each change we improved the weak link of the previous method. This was done only when the weak link became obvious, and the revised technique was then used in all subsequent replacements. The results are summarized in the Table, which shows the different systems used arranged in chronological sequence, the number of units used, the time range and mean duration of each satisfactory implant, and the causes of pacemaker failure in each case.

(1) Epicardial Electrodes with an Abdominal Implanted Generator (Elema E.M. $139^{1}$ or Devices $A^{2}$ ).-Eight units were implanted in seven patients. This system was unsatisfactorythe electrode wires fractured or became detached from the heart and bradycardia occurred, often with recurrent life-threatening Stokes-Adams attacks. The patients needed urgent readmission to hospital for an alternative system of pacing. In six of the eight cases the wires broke or became detached after 1 to 12 months, with a mean duration of successful pacing of four months.

(2) Transvenous Pacemaking Wire (U.S.C.I. C50 ${ }^{3}$ with an Axillary Generator (Devices $A$ or $X^{2}$ ).-An endocardial wire was used to avoid epicardial wire detachment. Seventeen units were inserted during a six-month period from November 1964. The generators manufactured at that time proved unreliable and battery or component failure occurred after 4 to 10 months in seven patients ; the mean duration of generator life was six months. In three other patients either the electrode wire fractured or the insulation covering cracked in the neck, producing failure after 5 to 10 months (mean, six months). Perforation of the ventricle occurred in two patients, two units failed because of exit block, and three other patients died of other causes (see Table). The "weak link," the Devices generator, was therefore replaced by the Elema unit.

(3) Transvenous Pacemaking Wire (U.S.C.I. C50) with an Axillary or Abdominal Generator (Elema E.M. 139).-Eight units were implanted. In six the outer insulating covering of the U.S.C.I. electrode wire fractured in the neck from repeated flexion stresses (Fig. 1). This short-circuited the output of

\footnotetext{
${ }^{1}$ Elema-Schönander, Stockholm, Sweden.

${ }^{2}$ Devices Ltd., Welwyn Garden City, Herts, England.

- United States Catheter Corporation, Glen Falls, U.S.A.
} 